\title{
Ocean gyres driven by surface buoyancy forcing
}

\author{
Andrew McC. Hogg ${ }^{1,2}$ and Bishakhdatta Gayen ${ }^{1,3}$ \\ ${ }^{1}$ Research School of Earth Sciences, Australian National University, Canberra, Australia. \\ ${ }^{2}$ ARC Centre of Excellence for Climate Extremes, Australian National University, Canberra, Australia. \\ ${ }^{3}$ Deparment of Mechanical Engineering, University of Melbourne, Australia.
}

\section{Key Points:}

- Simulations show that large-scale midlatitude ocean gyres can be driven by buoyancy forcing alone.

- Scaling balance to estimate the relative contributions of wind and buoyancy forcing to gyre circulation is evaluated.

- Estimates of gyre transport should take surface buoyancy forcing into account.

This is the author manuscript accepted for publication and has undergone full peer review but has not been through the copyediting, typesetting, pagination and proofreading process, which may lead to differences between this version and the Version of Record. Please cite this article as dor: 10.1029/2020GL088539

Corresponding author: Andrew Hogg and Bishakhdatta Gayen, Andy.Hogg@anu.edu.au and Bishakhdatta.Gayen@unimelb.edu.au 


\section{9

\begin{abstract}
Midlatitude gyres in the ocean are large scale horizontal circulations that are intensified on the western boundary of the ocean, giving rise to currents such as the Gulf Stream. The physical mechanism underlying gyres is widely recognised to involve the curl of the wind stress, which injects potential vorticity into the upper ocean. However, model results have highlighted the role of surface buoyancy fluxes (principally heating and cooling of the ocean surface) in driving circulation and enhancing gyre variability. Here we present two numerical simulations - one in the fully turbulent regime and the second an eddy-permitting ocean model - which show that gyre-like circulation can be driven by surface buoyancy fluxes alone. We explore this phenomenon through a combination of modelling and linear theory to highlight that the transport of ocean gyres depends upon surface buoyancy fluxes as well as wind stress.
\end{abstract}

\title{
Plain Language Summary
}

Ocean gyres are persistent, large-scale circulation features that give rise to important ocean currents such as the Gulf Stream in the North Atlantic and the Kuroshio current off the east coast of Japan. These gyres are critical in transporting heat from the tropics to the poles. Standard oceanographic theory suggests that these gyres are driven by wind stress, however, the simple theory that predicts the strength of these gyres fails in many parts of the ocean. In this manuscript we demonstrate that ocean gyres (complete with a rich eddy field and strong western boundary current) occur even in the absence of wind forcing. Thus, we contend that a significant component of gyre circulation, particularly in the subpolar regions, is due to temperature-driven buoyancy fluxes. This result represents a profound change to our understanding of one of the most fundamental aspects of the oceans large-scale circulation.

\section{Introduction}

Ocean circulation is primarily driven by a combination of mechanical forcing due to wind stress and buoyancy forcing (heating/cooling and freshening/salinification) at the ocean surface (Ferrari \& Wunsch, 2009; Hughes, Hogg, \& Griffiths, 2009; Stewart, Ferrari, \& Thompson, 2014; Tailleux, 2009). The relative influence of buoyancy and mechanical forcing on individual current systems is a major challenge of oceanographic research that aims to predict the response of the ocean circulation to climate change. Traditional oceanographic theory predicts that horizontal, near-surface currents are driven by wind (W. H. Munk, 1950), with the deep overturning circulation (involving vertical transport) driven by differences in buoyancy (Schmitz \& McCartney, 1993). This viewpoint has been revised in recent decades. Firstly, it has been recognised that an equilibrated ocean overturning circulation must balance the generation of buoyancy differences at the surface with turbulent mixing throughout the ocean (W. Munk \& Wunsch, 1998). This oceanic turbulence is powered by mechanical forces, including wind stress and the bottom stress induced by tidal flow (Ferrari \& Wunsch, 2009; Wunsch \& Ferrari, 2004). Secondly, the Antarctic Circumpolar Current (ACC) in the Southern Ocean is a surface-intensified current traditionally considered to be driven by wind stress (Johnson \& Bryden, 1989; W. H. Munk \& Palmèn, 1951). However, recent research suggests a strong role for buoyancy forcing in driving the mean ACC (Gent, Large, \& Bryan, 2001; Hogg, 2010), with wind stress primarily controlling the strength of the mesoscale eddy field (Hogg et al., 2015). Thus, the traditional delineation between near-surface winddriven flow and deep buoyancy-driven circulation no longer appears to hold. These advances motivate us to re-examine the cornerstone oceanographic theory of wind-driven gyres.

The oceanic wind-driven circulation is typically estimated by assuming a linear balance between the input of potential vorticity at the surface and meridional transport across 
gradients in planetary vorticity $\left(\beta=\frac{\partial f}{\partial y}\right.$, where $f$ is the Coriolis parameter and $y$ the meridional coordinate). This argument can be derived from Sverdrup balance for the geostrophic velocity, $v_{g}$ :

$$
\beta v_{g}=f \frac{\partial w}{\partial z} .
$$

If transport is integrated over the ocean depth $H$, then to first order, it can be shown (Wunsch, 2011) that the meridional transport is given by

$$
\beta v H=(\nabla \times \tau) \cdot \hat{\mathbf{z}}
$$

where $v$ is the vertically averaged meridional velocity, $\hat{\mathbf{z}}$ is the vertical unit vector and $\tau$ the wind stress vector (where stress is normalised by reference density). This is the Sverdrup transport relation (Sverdrup, 1947) commonly used to estimate barotropic meridional transport in the interior of ocean gyres, closed by an inertial return flow along the western boundary. The meridional variation in the wind stress thus governs the direction of meridional flow in these large-scale gyres: combined with the westward intensification of the return flow (Stommel, 1948) the subtropical gyre (equatorward of the maximum wind stress) spins in an anticyclonic sense (clockwise in the northern hemisphere), while the subpolar gyre (poleward of the maximum wind stress) rotates in a cyclonic direction. At the boundary between these gyres, which is predicted to occur at the location where wind stress curl is zero, western boundary currents separate from the coast to close the gyres.

The theory of wind-driven gyres has developed considerably over the succeeding decades, but the dependence of the circulation on wind stress curl has remained a key element of any theory. The ventilated thermocline theory (Luyten, Pedlosky, \& Stommel, 1982) uses a layered framework to demonstrate that the vertical structure of the solution depends upon stratification. However, under this model, only isopycnal layers that outcrop at the surface have a circulation; integration over the active layers recovers the Sverdrup relation. Furthermore, it should be stressed that the linear balance in Eq. (2) is complicated by nonlinear processes such as eddies; this can result in homegenisation of potential vorticity (Rhines \& Young, 1982) and the creation of strong inertial recirculation gyres (Cessi, 1988; Cessi, Ierley, \& Young, 1987) overprinting the linear circulation.

Nonlinearity and stratification complicate the evaluation of Sverdrup dynamics in the ocean. Combining Argo float trajectories and density profiles, Gray and Riser (2014) argue that Sverdrup balance (Eq. 1) is in agreement with observations in the subtropical gyres, consistent with Wunsch (2011). Quantitatively, the zonally averaged Sverdrup balance in ocean reanalysis products and models is accurate to within $20 \%$ (Thomas, de Boer, Johnson, \& Stevens, 2014). Sverdrup balance is less accurate in the subpolar gyres (Gray \& Riser, 2014) implying that bottom topography steers the current (Bower et al., 2002; Yeager, 2015). Colin de Verdière and Ollitrault (2016) further apply boundary constraints on the known ocean density field and Argo float trajectories to infer that the Sverdrup transport relation (Eq. 2) underestimates the barotropic circulation by approximately a factor of two in subtropical gyres.

An alternative hypothesis for the generation of large scale horizontal circulation in ocean basins is that it may be driven by surface buoyancy fluxes. This notion was first proposed by Goldsbrough (1933), who predicted a weak circulation to arise through the sea level variations owing to freshwater fluxes. Comparisons of wind-driven with buoyancy driven flow were also investigated by Luyten and Stommel (1986), but their simple model parameterised the buoyancy contribution as a diabatic interior flux, rather than buoyancy flux through the surface of the ocean. Colin de Verdière (1988) outlined theoretical and numerical predictions to demonstrate large-scale gyre circulations could be driven by buoyancy forcing alone. In particular, surface buoyancy forcing may contribute to potential vorticity entry or exit (Czaja \& Hausmann, 2009), hence creating horizontal circulation on par with wind-driven gyres (Colin de Verdière, 1989). More recently, 
coarse-resolution global ocean models run in the absence of wind stress forcing have helped to reinitiate the discussion about the relative roles of wind stress and buoyancy fluxes in driving large scale circulation (Gjermundsen, LaCasce, \& Denstad, 2018). However, these previous studies produced a single large gyre and were unable to recreate the double gyre structure observed in the ocean.

In this paper we investigate the role of surface buoyancy forcing as an additional forcing of gyres using turbulence resolving and eddy-permitting numerical simulations. In our simulations, we define the gyres to be horizontal, recirculating, basin-scale mean flows, that are balanced by inertial western boundary currents. We compare both barotropic and baroclinic measures of the gyre strength with predictions from linear theory, to evaluate whether gyres forced solely by surface buoyancy fluxes may be significant contributors to the large-scale ocean circulation.

\section{Scaling}

The buoyancy budget of the upper ocean can be approximated by integrating the advection-diffusion equation for density over a layer of constant depth $h$, assuming a linear equation of state. We further assume that advective contributions are dominated by the depth-averaged velocity $(u, v)$ with negligible vertical velocity, while diffusive contributions are dominated by vertical fluxes to give

$$
\frac{\partial b}{\partial t}+u \frac{\partial b}{\partial x}+v \frac{\partial b}{\partial y}=\frac{F_{S}}{h}-\frac{F_{h}}{h},
$$

where $b$ is the depth-averaged buoyancy (related to the depth-averaged ocean density, $\rho$, by $b=g\left(\rho_{0}-\rho\right) / \rho_{0} ; g$ being the acceleration due to gravity). Thus, the vertical buoyancy flux at the surface $\left(F_{S}\right)$ and at depth $h\left(F_{h}\right)$ balances the lateral advection of buoyancy. A Reynolds decomposition of the flow, in which we divide the flow in to mean $(\bar{b}(y))$ and transient $\left(b^{\prime}\right)$ components, gives

$$
\bar{v} \frac{\partial \bar{b}}{\partial y}+\overline{\mathbf{u}^{\prime} \cdot \nabla b^{\prime}} \approx \frac{\overline{F_{S}}}{h},
$$

if $F_{h}$ is assumed negligible. By analogy with the Sverdrup transport relation, in which the potential vorticity budget is linearised about a background state, Eq. (3) is linearised to eliminate the eddy buoyancy fluxes $\left(\overline{\mathbf{u}^{\prime} \cdot \nabla b^{\prime}}\right)$, leaving a zeroth order balance between meridional advection of buoyancy and the surface forcing,

$$
\bar{v} \sim \frac{F_{S}}{h \frac{\partial \bar{b}}{\partial y}} .
$$

Equation (5) describes a type of Walin balance (Walin, 1982) in which meridional flow in the ocean scales with surface buoyancy flux. It cannot be used to predict the circulation, but can be used in diagnostic mode. As with Sverdrup balance, it assumes that nonlinearity and eddy fluxes are secondary effects, and suggests equatorward flow in the subtropical ocean (assuming that $F_{S}$ is generally positive there) and poleward flow in subpolar regions. This relationship may break down when vertical fluxes are significant, and is difficult to apply to real-world scenarios where neither $\bar{b}$ nor $F_{S}$ is independent of longitude. Importantly, Eq. (5) does not replace Sverdrup balance; instead, vorticity and buoyancy must both be balanced, implying that gyre strength should depend upon buoyancy fluxes, as well as wind stress curl.

\section{Models}

Two different methods are used to understand the dynamics of buoyancy-forced gyres. The first method is a Direct Numerical Simulation in which all scales of turbulence in a fluid domain are resolved but the scales and aspect ratio differ from the ocean. 
The second method is to use an eddy-permitting ocean model that has parameterised mixing and convection but can resolve the ocean aspect ratio and additionally incorporate the relative effects of wind stress. These two methods are used to highlight, firstly, the fundamental nature of buoyancy-driven circulation in a rotating fluid and, secondly, to compare the magnitude of buoyancy-driven circulation with that driven by wind; each are outlined in detail in the following subsections.

\subsection{Direct Numerical Simulation}

Three-dimensional Navier-Stokes, advection-diffusion and continuity equations were solved in the incompressible, nonhydrostatic, Boussinesq approximation in a rotating coordinate frame using Direct Numerical Simulation (DNS). The flow solution assumes a linear equation of state with density solely dependent on temperature, and is calculated in dimensionless form. The algorithm and approach has previously been described and tested for large Rayleigh number convection (Gayen, Griffiths, \& Hughes, 2014; Gayen, Hughes, \& Griffiths, 2013; Vreugdenhil, Gayen, \& Griffiths, 2016). We consider a rectangular basin geometry of length and width $L$ and water depth $H$, with an aspect ratio $A=H / L=0.2$. No-normal flow and no-slip boundaries for velocity and no flux temperature condition were used at the side-walls and bottom surface. A stress-free condition for velocity was imposed at the upper surface, and upper surface boundary temperature is prescribed as $T=\Delta T|\sin (\pi y / 2 L)|$, where $(x, y)$ are horizontal coordinates and $\Delta T$ is the maximum temperature difference; flux into the fluid domain occurs through molecular diffusion. The thermal forcing is expressed in terms of the dimensionless Rayleigh number $R a=g \alpha \Delta T L^{3} / \kappa \nu$, with gravitational acceleration $g$, applied temperature difference $\Delta T$ across the basin length, and the fluids thermal expansion coefficient $\alpha$, molecular diffusivity of heat $\kappa$ and molecular kinematic viscosity $\nu$. We use variable Coriolis frequency represented by $f=f_{0} \sin (\pi y / 2 L)$; we omit the non-traditional Coriolis terms despite simulating in the non-hydrostatic regime. The strength of rotation is represented by the Rossby number $R o=u_{g} / L f_{0}$ where $u_{g}=g \alpha \Delta T / f_{0}$ is geostrophic velocity scale. Simulations are performed at $R a=8 \times 10^{11}, R o=0.037$ and Prandtl number $\operatorname{Pr}=5$. In dimensional terms, assuming molecular values of viscosity, the domain of this simulation is on the laboratory scale - approximately $1 \mathrm{~m}$ horizontal and $20 \mathrm{~cm}$ deep, and the reduced gravity, $g \alpha \Delta T \approx 0.15 \mathrm{~m} \mathrm{~s}^{-2}$.

The solution grid for the DNS is $1536 \times 1536 \times 512$ cells, clustered to resolve the upper thermal boundary layer and bottom Ekman layer, side boundary layers on the vertical walls and active convection areas. The grid resolution $[\Delta x, \Delta y, \Delta z]$ is comparable to the Batchelor microscale $\eta_{b}=\left(\nu^{3} / \varepsilon^{*}\right)^{1 / 4} \mathrm{Pr}^{-1 / 2}$ (where $\varepsilon^{*}$ is the local dissipation rate) to ensure the resolution criterion $\eta_{b} \geq[\Delta x, \Delta y, \Delta z]_{\max }$ is satisfied and the smallest scales of motion are accurately resolved everywhere in this domain (Gayen et al., 2014). Most importantly, adequate resolution was confirmed by accurate closure of the mechanical energy budget (Gayen et al., 2014; Vreugdenhil, Gayen, \& Griffiths, 2016). Thermal equilibrium was achieved when secular change in the energetic quantities was not detectable, with net heat input continuing to fluctuate about zero with amplitude of the order of $1.5 \%$ of the heat throughput.

\subsection{Ocean Model Simulations}

The Direct Numerical Simulation is designed to resolve all scales of turbulence and convection, but has a larger aspect ratio and smaller Rayleigh number than the ocean. Hence, DNS techniques cannot be used to estimate the relative magnitude of gyres driven by buoyancy and wind stress. These questions are addressed using an eddy-permitting $\left(0.25^{\circ}\right)$ ocean circulation model in an idealised domain (Fig. 1). We use MOM6 (Adcroft et al., 2019) in a rectangular domain spanning $40^{\circ}$ in longitude and from the Equator to $70^{\circ} \mathrm{N}$ in latitude, with $0.25^{\circ}$ resolution on a Mercator grid and 75 vertical levels (using the $z^{*}$ vertical coordinate) in a $4000 \mathrm{~m}$ deep basin. The Equatorial boundary includes 

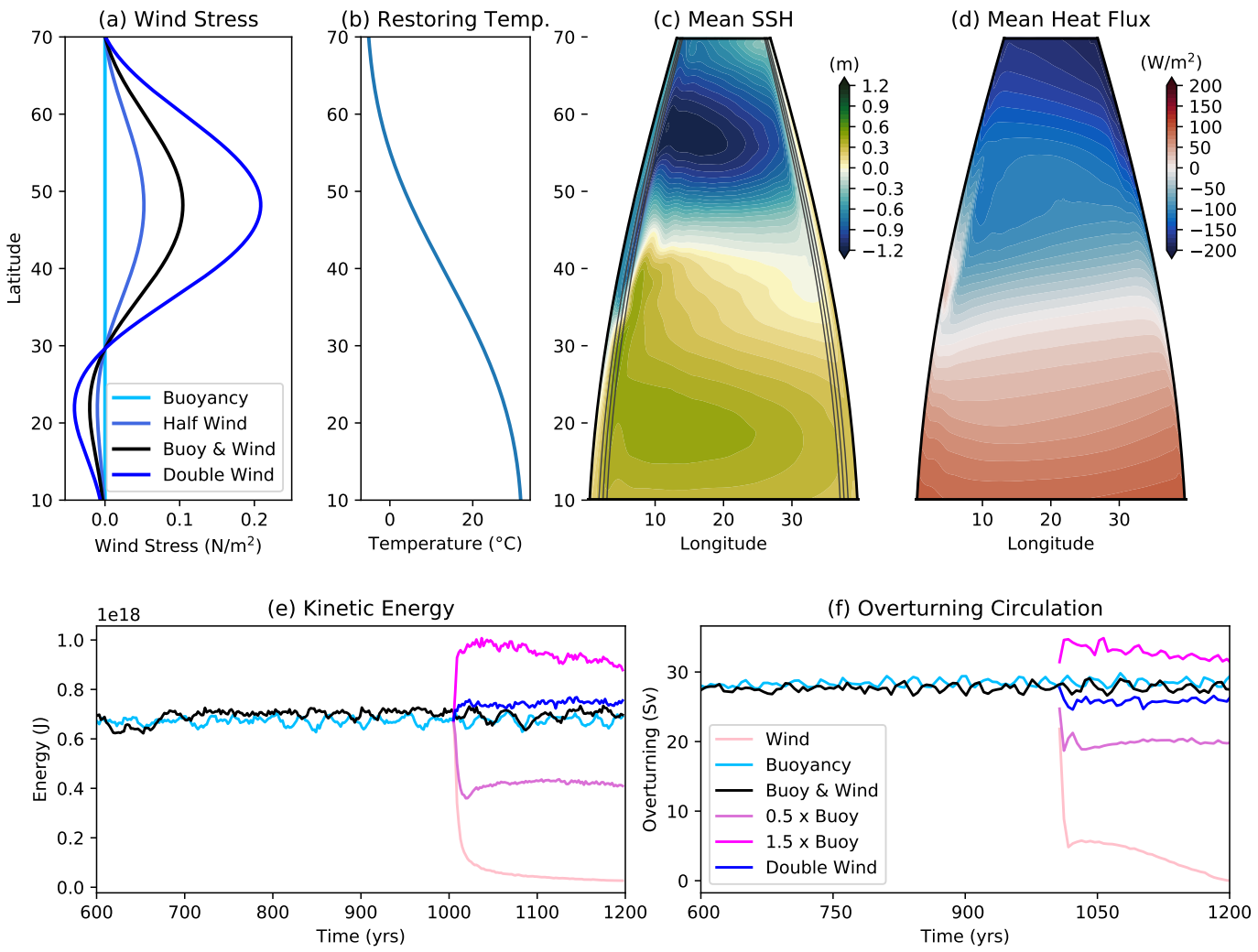

a thin $\left(3^{\circ}\right.$ wide $)$ region in which vertical diffusivity is enhanced by a factor of 500 to close the overturning circulation. Other side boundaries are insulating, with a vertical wall in the north and sloping sidewalls to the east and west. The surface forcing includes steady zonal wind stress, $\tau$, and temperature restoring to a meridionally symmetric profile with piston velocity $F_{C}$, equivalent to a restoring flux, $\lambda=\rho C_{p} F_{c}$ in $\mathrm{W} \mathrm{m}^{-2} \mathrm{~K}^{-1}$ (see Haney, 1971). The equation of state depends linearly on temperature. The upper ocean has an amplified diffusivity (up to $K_{\rho}=2 \times 10^{-3} \mathrm{~m}^{2} / \mathrm{s}$ in the reference case, compared with $K_{\rho}=2 \times 10^{-5} \mathrm{~m}^{2} / \mathrm{s}$ in the interior) as a crude parameterization for mixed layer turbulence (Vreugdenhil, Hogg, Griffiths, \& Hughes, 2016). Convection is handled via CVMix whereby diffusivity is enhanced at statically unstable interfaces. The surface forcing permits variation of the wind stress $(\tau)$ and buoyancy forcing $\left(F_{C}\right)$ that can be varied independently, noting the difficulty of unambiguously separating the forcing components in such a nonlinear system.

Figure 1. Ocean model configuration. (a) Wind stress; (b) Surface restoring temperature field; (c) Mean sea surface height in reference case, with topography indicated by contours; (d) Mean surface heat flux for reference case; (e) Time series of domain-wide kinetic energy; and (f) Time series of the residual overturning circulation calculated in density space and evaluated at $20-30^{\circ} \mathrm{N}$ for 6 selected cases.

Eight experiments are conducted. The reference case (referred to as Buoyancy \& Wind) uses control values of wind stress (black line in Fig. 1a with $\tau_{\max }=0.1 \mathrm{~N} \mathrm{~m}^{-2}$ ), with the buoyancy flux via the temperature restoring profile from Fig. $1 \mathrm{~b}$ (with $F_{C}=$ $0.2 \mathrm{~m} /$ day, equivalent to $\lambda \approx 10 \mathrm{~W} \mathrm{~m}^{-2} \mathrm{~K}^{-1}$ ). The reference case is run for 1200 years to demonstrate full equilibration. We vary wind stress, with a Double Wind case, a Half Wind case and an additional case with no wind stress forcing (referred to as Buoyancy; 
Fig. 1a) with each simulation run for 200 years from the year 1000 state of the Reference simulation as the initial condition. To further demonstrate equilibration, we run the Buoyancy case for the full 1200 years, and also as a 200 year perturbation, with results indistinguishable (see Fig. S1, Supplementary Material). We vary buoyancy flux by varying $F_{C}$ from 0.0 through to $0.3 \mathrm{~m} /$ day. Note that the Wind case, in which buoyancy flux is completely switched off $\left(F_{C}=0.0 \mathrm{~m} /\right.$ day $)$ erodes the stratification to generate a barotropic flow after $\sim 100$ years.

\section{Results}

\subsection{Direct Numerical Simulation}

The role of buoyancy forcing in driving ocean gyres is first tested using Direct Numerical Simulation (DNS). We apply differential thermal forcing to the surface of an idealised domain (heating in the south, cooling in the north) with low Rossby number ( $R o=$ $0.037)$ to simulate planetary rotation and large Rayleigh number $\left(R a=8 \times 10^{11}\right)$ to maintain turbulent convection. This convection is active over the northern part of the domain where cooling destabilizes the water column, forming vertical plumes that extend through the full depth of the box (vertical velocity plane in Fig. 2). A northward current forms along the eastern boundary where it is held against the boundary by Coriolis force. This current initiates cyclonic gyre circulation filling the width of the box over the cooling region as shown by the depth-averaged streamfunction (blue contours, upper plane of Fig. 2). Thus, even in the absence of wind forcing, a cyclonic gyre forms analogous to an oceanic subpolar gyre.

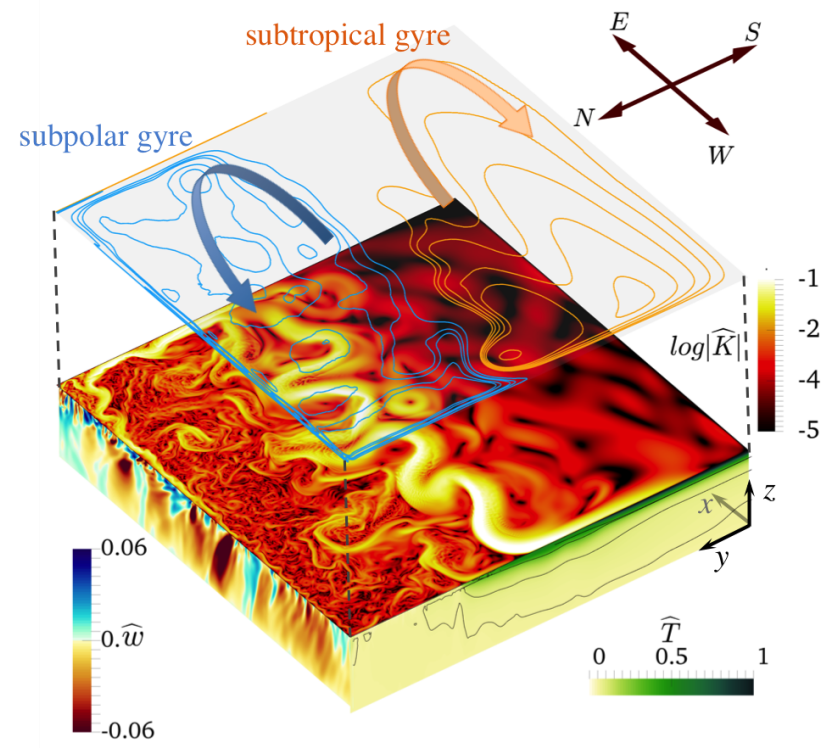

Figure 2. Snapshot of DNS illustrating the character of buoyancy forced ocean gyre circulation. The horizontal plane shows normalized kinetic energy $1 / 2\left[u^{2}+v^{2}+w^{2}\right] /\left(g^{\prime} / f_{0}\right)^{2}$ (on a logarithmic scale) on the plane $z=H$. The panel on the northern boundary shows vertical velocity $w$ normalized by $g^{\prime} / f_{0}$ (upward in blue, downward in brown) at $y=0.95 L$. The panel on the western boundary shows the normalized temperature field $\left(T-T_{C}\right) / \Delta T$ at $x=0.05 L$. These two planes are within their respective lateral boundary layers. The elevated floating plane shows contours of mean depth-integrated streamfunction. Gravity is oriented vertically downwards, rotation is anticlockwise and solutions are obtained at a thermally equilibrated state. 
Conversely, in the southern part of the domain, heating stabilizes the flow (see the $y-z$ plane in Fig. 2). Here, the barotropic streamfunction indicates a southward interior transport (consistent with Eq. 5), with a northward current of warm water along the western boundary. This current is intensified by the presence of Rossby waves, which propagate from east to west (see supporting movie). The current separates from the boundary near the mid-point of the domain (also the location of the negligible heat input, analogous to the latitude of negligible wind stress curl in Sverdrup theory) and travels eastward across the basin, constrained by thermal wind balance (Vallis, 2006). This current is baroclinically unstable and produces a rich mesoscale eddy field. The western boundary current and eastward geostrophic basin-scale flow, along with weak southward interior flow, form a large-scale anticyclonic gyre. The double-gyre structure found here differs from the single dominant gyres found in previous simulations (Colin de Verdière, 1988; Gjermundsen et al., 2018), suggesting that resolving finer scales in the flow may be important for generating realistic buoyancy-driven gyres. The circulation in this simulation is broadly consistent with oceanic midlatitude gyre circulation, despite the absence of any wind stress forcing in these simulations, demonstrating the principle that gyres could be driven by buoyancy fluxes alone.

\subsection{Ocean model simulations}

The ocean model simulations constructed here use high resolution to explicitly represent eddy fluxes; simulations conducted at lower resolution $\left(1^{\circ}\right.$ lateral resolution with parameterised eddies) show a very different character in the circulation (see Fig. S2, Supplementary Material). The model is forced by a combination of wind stress and surface buoyancy fluxes (Fig. 1), which are varied independently in 8 different experiments. The ocean model state is averaged over the last 100 years of a 200-year perturbation to estimate the circulation (Fig. 3).

The barotropic (depth-integrated) circulation in these experiments (Fig. 3a-e) emphasises the formation of gyre-like circulation in the subpolar region (north of $45^{\circ} \mathrm{N}$ ) of this idealised domain. When only wind stress forcing is applied (Fig. 3a), a subpolar gyre arises that closely matches the prediction of Sverdrup balance. With only buoyancy forcing (Fig. 3b) a gyre still exists, noting that the northward meridional circulation in this case is dominated by transport along the Eastern boundary. Importantly, however, the spatial extent of the gyre is similar to the Wind case, and incorporates an inertial western boundary current that separates from the coast at mid-latitudes. Buoyancy and wind together (Fig. 3c) produce a stronger gyre in which elements of both interior and eastern boundary transport combine. Further strengthening either the wind or buoyancy forcing acts to enhance the circulation in this gyre.

The barotropic (depth-averaged) subtropical gyre (Equatorward of $40^{\circ} \mathrm{N}$ ) in these experiments is relatively weak, but we show below that stronger horizontal circulation occurs above the thermocline, similar to the circulation proposed in the ventilated thermocline theory (Luyten et al., 1982). To highlight the nature of this upper layer circulation, we follow Luyten et al. (1982) in selecting an isopycnal which outcrops close to the zero wind stress curl line $\left(\rho=1034 \mathrm{~kg} \mathrm{~m}^{-3}\right)$ and integrate transport above this isopycnal. To connect the upper layer transport to the ventilated thermocline theory, we remove the contribution of the meridional overturning circulation which flows northwards in the upper lower and southwards at depth; specifically, we calculate the basin- and layeraveraged transport at $10^{\circ} \mathrm{N}$ and subtract this transport from the streamfunction at all latitudes. The remainder gives a streamfunction which clearly delineates a subtropical upper-layer circulation (Fig. $3 \mathrm{f}-\mathrm{j}$ ). This gyre-like circulation is consistent with mean Sea Surface Height in these experiments, which is shown in Fig. S3.

The isopycnal we have used to define the upper ocean transport is found at 500$800 \mathrm{~m}$ depth in most experiments; the main exception being the Wind only case (Fig. 3f) 

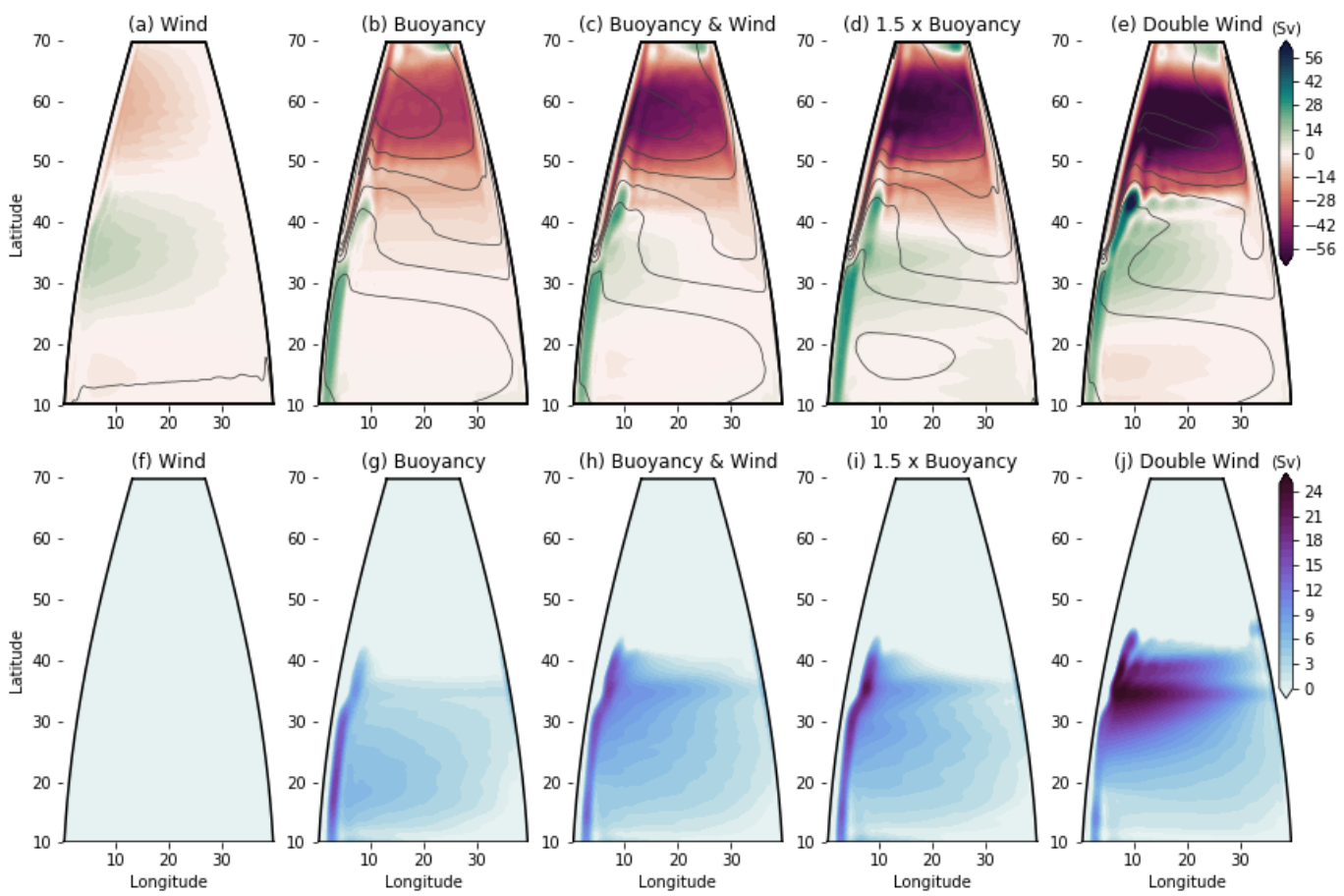

Figure 3. Mean circulation for selected ocean model simulations. (a-e) Barotropic mean streamfunction, overlain with contours of mean Sea Surface Temperature (Contour Interval $2^{\circ} \mathrm{C}$ ); (f-j) Upper streamfunction, which selects the subtropical gyre above the thermocline. The cases shown are (a,f) Wind forcing only, noting that the upper ocean streamfunction in (f) is not defined; (b,g) Buoyancy forcing only; (c,h) Reference case with Buoyancy \& Wind stress together; $(\mathrm{d}, \mathrm{i})$ Reference wind stress with increased buoyancy flux, and (e,j) Reference buoyancy with doubled wind stress.

where this isopycnal does not exist. However, in the reference case with Buoyancy and Wind forcing (Fig. 3h), the linear component of the gyre at $20-30^{\circ} \mathrm{N}$ closely matches Luyten et al.'s (1982) ventilated thermocline prediction, noting the formation of a stronger, inertial gyre close to the latitude western boundary current separation. This nonlinear recirculation is amplified by stronger wind forcing (Fig. 3j), but is relatively insensitive to additional buoyancy flux (Fig. 3i). Nonetheless, in the Buoyancy-only case (Fig. 3g) a linear gyre with transport of around $10 \mathrm{~Sv}$ is generated.

We now make a quantitative comparison of the gyre circulation in both the barotropic and upper ocean streamfunctions. We calculate the transport in each experiment at $10^{\circ} \mathrm{E}$ to avoid the contribution of nonlinear flow on the western boundary. We take the absolute value of the minimum barotropic streamfunction to represent the subpolar gyre transport (Fig. 4a,c,d), and the maximum value of the upper ocean circulation to represent the subtropical gyre transport (Fig. 4b,e,f). The timeseries of selected cases (Fig. $4 \mathrm{a}, \mathrm{b})$ confirm that the circulation is in equilibrium after $O(100)$ years of the perturbation simulations.

The barotropic subpolar gyre strength (averaged over the last 100 years) varies linearly with heat flux (Fig. 4c) and is consistent with predictions from Eq. (5) (evaluated for $h=1500 \mathrm{~m}$ and from $45^{\circ} \mathrm{N}-60^{\circ} \mathrm{N}$, where the meridional temperature gradient is maximum; see Fig. S4). The subpolar gyre also increases linearly with wind stress (Fig. 4d), however is $\sim 50 \mathrm{~Sv}$ larger than the linear Sverdrup transport prediction. We infer from 

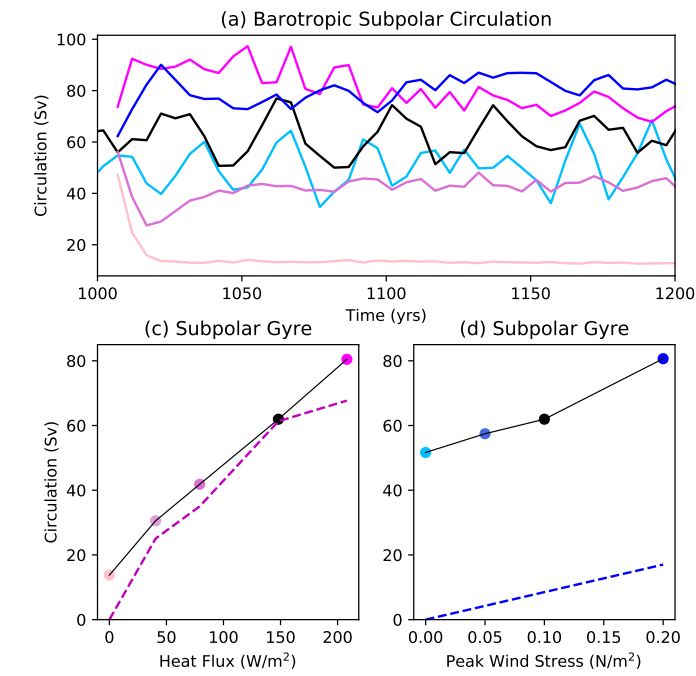
ancy forcing in contributing to large scale ocean gyres.

this result that the barotropic circulation of the subpolar gyre in this model is governed primarily by surface buoyancy flux, consistent with Eq. (5).

On the other hand, the upper layer circulation in the subtropical gyre is similar to the ventilated thermocline prediction (estimated by the blue dashed line in Fig. 4f), particularly at large values of wind stress. At lower values of wind stress a small (10 Sv) circulation persists, which we infer is driven by surface buoyancy forcing; however, the dependence of the circulation on surface buoyancy flux is over-predicted by Eq. (5) (see Fig. 4e), implying that the simplifications made in formulating that balance are not valid in the regime of these experiments. We assume that the most significant omission is that of eddy fluxes (Eq. 4), and infer from this result that linear theory is insufficient to predict the formation of the buoyancy-forced subtropical gyre in these simulations. Nonetheless, the existence of a finite baroclinic subtropical gyre (Fig. 3g and cyan dot in Fig. 4f) - alongside a barotropical subtropical gyre (Fig. 3b and cyan dot in Fig. 4d) - in the absence of any wind stress forcing confirm the critical importance of surface buoy-
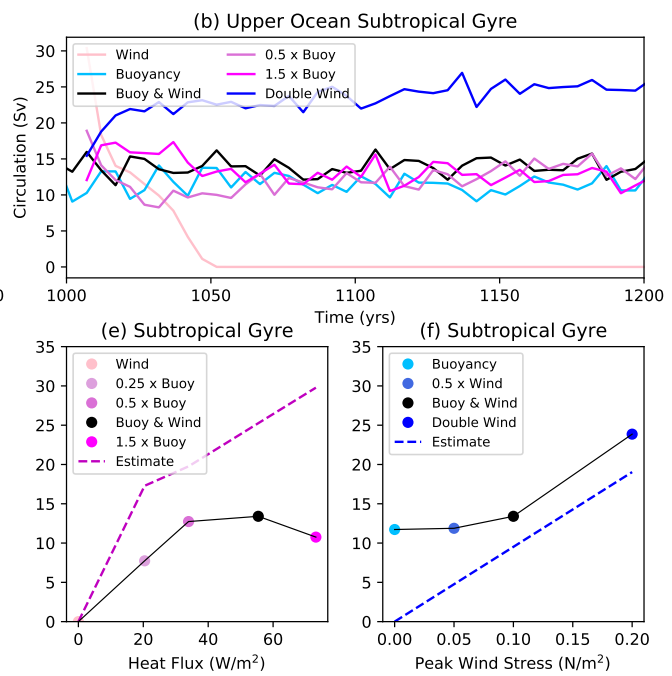

Figure 4. Integrated statistics for ocean model simulations and comparison with scaling. Time series of: (a) Barotropic subpolar gyre transport, and (b) Subtropical upper ocean gyre transport. Subpolar gyre dependence on: (c) heat flux and (d) wind stress; subtropical gyre dependence on (e) heat flux and (f) wind stress. Dashed lines show theoretical scaling, estimated from (c) Eq. (5) using the upper $1500 \mathrm{~m}$ depth-averaged meridional temperature gradient from $45^{\circ} \mathrm{N}-60^{\circ} \mathrm{N}$; (d) The Sverdrup transport relation (Eq. 2); (e) Equation (5) using the upper 500m depth-averaged meridional temperature gradient $20^{\circ} \mathrm{N}-35^{\circ} \mathrm{N}$, and (f) ventilated thermocline theory (Luyten et al., 1982).

\section{Discussion \& Conclusions}

The theoretical framework and the numerical model results presented here suggest that the accepted moniker "wind-driven gyres" is an incomplete description of the midlatitude ocean circulation. The notion that buoyancy forcing contributes to the transport of, particularly, the subpolar gyre is robust across several levels of idealisation, implying that these results may apply to the ocean. This notion is consistent with earlier studies on buoyancy driven gyres (e.g. Colin de Verdière, 1988), but is more significant when modelled in the eddying regime. In particular, previous attempts to model buoy- 
ancy driven gyres at lower resolution (Colin de Verdière, 1988; Gjermundsen et al., 2018) tended to create a single large-scale gyre in each basin; in the eddy permitting configuration we find that a more realistic double gyre, with an inertial western boundary current, emerges naturally even in the absence of wind stress. We reiterate that these results are not intended to replace the theory of wind-driven gyres, but merely to point out that a component of the gyre circulation, particularly in subpolar regions, can be forced by surface buoyancy flux.

The simulations in this study are compared with estimates based on linear theory. These comparisons highlight that the theories employed are unable to fully describe the system: in particular, linear buoyancy theory overpredicts the baroclinic subtropical gyre, while the Sverdrup transport equation underpredicts the barotropic subpolar gyre circulation in these simulations. However, the sensitivity of the subpolar gyre to buoyancy forcing, in combination with the existence of significant subpolar and subtropical gyre structures in the absence of wind stress, underscores the importance of incorporating surface buoyancy fluxes into our understanding of gyre circulation.

\section{Acknowledgments}

The authors thank Ross Griffiths, Michael Roderick, Matthew England and Nerilie Abram for their comments on this paper. This research was funded by Australian Research Council grant DP140103706. BG was supported by RJL Hawke Fellowship AAS 4422 and ARC Future Fellowship (FT180100037). This research was undertaken with the assistance of resources and services from the National Computational Infrastructure (NCI), which is supported by the Australian Government. This manuscript is based on output from highresolution numerical models; processed output to support the analysis is published with doi: $10.5281 /$ zenodo.3768500.

\section{References}

Adcroft, A., Anderson, W., Balaji, V., Blanton, C., Bushuk, M., Dufour, C. O., ... Zhang, R. (2019). The GFDL Global Ocean and Sea Ice Model OM4.0: Model Description and Simulation Features. J. Adv. Model. Earth Syst., 3167-3211. doi: $10.1029 / 2019 \mathrm{MS} 001726$

Bower, A. S., Le Cann, B., Rossby, T., Zenk, W., Gould, J., Speer, K., ... Zhang, H. M. (2002). Directly measured mid-depth circulation in the northeastern north atlantic ocean. Nature, 419 (6907), 603-607. doi: 10.1038/nature01078

Cessi, P. (1988). A stratified model of the inertial recirculation. J. Phys. Ocean., 18, $662-682$.

Cessi, P., Ierley, G., \& Young, W. (1987). A model of the inertial recirculation driven by potential vorticity anomalies. J. Phys. Ocean., 17, 1640-1652.

Colin de Verdière, A. (1988). Marine Research. J. Mar. Res., 46(2), 215-265. doi: $10.1357 / 002224088785113667$

Colin de Verdière, A. (1989). On the interaction of wind and buoyancy driven gyres. Journal of Marine Research, 47(3), 595-633. doi: 10.1357/ 002224089785076172

Colin de Verdière, A., \& Ollitrault, M. (2016). A Direct Determination of the World Ocean Barotropic Circulation. J. Phys. Oceanogr., 46(1), 255-273. doi: 10 $.1175 /$ jpo-d-15-0046.1

Czaja, A., \& Hausmann, U. (2009). Observations of entry and exit of potential vorticity at the sea surface. Journal of Physical Oceanography, 39(9), 2280-2294. doi: $10.1175 / 2009$ jpo4024.1

Ferrari, R., \& Wunsch, C. (2009). Ocean circulation kinetic energy: Reservoirs, sources, and sinks. Annu. Rev. Fluid Mech., 41(1), 253-282. doi: 10.1146/ annurev.fluid.40.111406.102139

Gayen, B., Griffiths, R. W., \& Hughes, G. O. (2014). Stability transitions and tur- 
bulence in horizontal convection. J. Fluid Mech., 751, 698-724. doi: 10.1017/ jfm.2014.302

Gayen, B., Hughes, G. O., \& Griffiths, R. W. (2013). Completing the mechanical energy pathways in turbulent rayleigh-bénard convection. Phys. Rev. Lett., $111(12), 124301$.

Gent, P. R., Large, W. G., \& Bryan, F. O. (2001). What sets the mean transport through drake passage? J. Geophys. Res. Oceans, $106(\mathrm{C} 2), 2693-2712$. doi: 10 .1029/2000JC900036

Gjermundsen, A., LaCasce, J. H., \& Denstad, L. (2018). The Thermally Driven Ocean Circulation with Realistic Bathymetry. J. Phys. Oceanogr., 48(3), 647665. doi: $10.1175 / J P O-D-17-0147.1$

Goldsbrough, G. R. (1933). Ocean currents produced by evaporation and precipitation. Proc. R. Soc. Lond. A., 141, 512-517. doi: 10.1098/rspa.1933.0135

Gray, A. R., \& Riser, S. C. (2014). A global analysis of sverdrup balance using absolute geostrophic velocities from argo. J. Phys. Oceanogr., 44(4), 1213-1229. doi: $10.1175 /$ jpo-d-12-0206.1

Haney, R. L. (1971). Surface Thermal Boundary Condition for Ocean Circulation Models. J. Phys. Oceanogr., 1(4), 241-248. doi: 10.1175/1520-0485(1971) 001<0241:STBCFO $\rangle 2.0 . \mathrm{CO} ; 2$

Hogg, A. M. (2010). An Antarctic Circumpolar Current driven by surface buoyancy forcing. Geophys. Res. Lett., 37(23), L23601. doi: 10.1029/2010GL044777

Hogg, A. M., Meredith, M. P., Chambers, D. P., Abrahamsen, E. P., Hughes, C. W., \& Morrison, A. K. (2015). Recent trends in the southern ocean eddy field. $J$. Geophys. Res. Oceans, 120(1), 257-267. doi: 10.1002/2014JC010470

Hughes, G. O., Hogg, A. M., \& Griffiths, R. W. (2009). Available potential energy and irreversible mixing in the meridional overturning circulation. J. Phys. Oceanogr., 39(12), 3130-3146. doi: 10.1175/2009jpo4162.1

Johnson, G. C., \& Bryden, H. L. (1989). On the size of the antarctic circumpolar current. Deep Sea Res. Part A., 36(1), 39-53. doi: 10.1016/0198-0149(89)90017 $-4$

Luyten, J., Pedlosky, J., \& Stommel, H. (1982). The ventilated thermocline. $\quad J$. Phys. Ocean., 13, 292--309.

Luyten, J., \& Stommel, H. (1986). Gyres Driven by Combined Wind and Buoyancy Flux. J. Phys. Oceanogr., 16 (9), 1551-1560. doi: 10.1175/1520-0485(1986) 016<1551:gdbcwa $>2.0 . c 0 ; 2$

Munk, W., \& Wunsch, C. (1998). Abyssal recipes ii: energetics of tidal and wind mixing. Deep Sea Res., 45(12), 1977-2010. doi: 10.1016/S0967-0637(98)00070 $-3$

Munk, W. H. (1950). On the wind-driven ocean circulation. J. Met., 7(2), 80-93. doi: 10.1175/1520-0469(1950)007<0080:otwdoc $\rangle 2.0 . c 0 ; 2$

Munk, W. H., \& Palmèn, E. (1951). Note on the dynamics of the antarctic circumpolar current. Tellus, 3(1), 53-55. doi: 10.1111/j.2153-3490.1951.tb00776.x

Rhines, P. B., \& Young, W. R. (1982). Homogenization of potential vorticity in planetary gyres. J. Fluid Mech., 122, 347-367. doi: 10.1017/ S0022112082002250

Schmitz, W. J., \& McCartney, M. S. (1993). On the north atlantic circulation. Rev. Geophys., 31(1), 29-49. doi: 10.1029/92RG02583

Stewart, A. L., Ferrari, R., \& Thompson, A. F. (2014). On the importance of surface forcing in conceptual models of the deep ocean. J. Phys. Oceanogr., 44(3), 891-899. doi: 10.1175/jpo-d-13-0206.1

Stommel, H. (1948). The westward intensification of wind-driven ocean currents. Eos, Transactions American Geophysical Union, 29(2), 202-206. doi: 10.1029/ TR029i002p00202

Sverdrup, H. U. (1947). Wind-driven currents in a baroclinic ocean; with application to the equatorial currents of the eastern pacific. Proc. Natl. Acad. Sci. 
USA, 33(11), 318-326.

Tailleux, R. (2009). On the energetics of stratified turbulent mixing, irreversible thermodynamics, boussinesq models and the ocean heat engine controversy. $J$. Fluid Mech., 638, 339-382. doi: 10.1017/S002211200999111X

Thomas, M. D., de Boer, A. M., Johnson, H. L., \& Stevens, D. P. ～(2014). Spatial and temporal scales of sverdrup balance. J. Phys. Oceanogr., 44(10), 26442660. doi: $10.1175 /$ jpo-d-13-0192.1

Vallis, G. K. (2006). Atmospheric and oceanic fluid dynamics [Book]. Cambridge, U.K.: Cambridge University Press.

Vreugdenhil, C. A., Gayen, B., \& Griffiths, R. W. (2016). Mixing and dissipation in a geostrophic buoyancy-driven circulation. J. Geophys. Res. Oceans, 121(8), 6076-6091. doi: 10.1002/2016JC011691

Vreugdenhil, C. A., Hogg, A. M., Griffiths, R. W., \& Hughes, G. O. (2016). Adjustment of the meridional overturning circulation and its dependence on depth of mixing. J. Phys. Oceanogr., 46(3), 731-747. doi: 10.1175/jpo-d-15-0050.1

Walin, G. (1982). On the relation between sea-surface heat flow and thermal circulation in the ocean. Tellus, 34(2), 187-195. doi: 10.1111/j.2153-3490.1982 .tb01806.x

Wunsch, C. (2011). The decadal mean ocean circulation and Sverdrup balance. $J$. Mar. Res., 69(2-3), 417-434. doi: 10.1357/002224011798765303

Wunsch, C., \& Ferrari, R. (2004). Vertical mixing, energy, and the general circulation of the oceans. Annu. Rev. Fluid Mech., 36(1), 281-314. doi: 10.1146/ annurev.fluid.36.050802.122121

Yeager, S. (2015). Topographic coupling of the atlantic overturning and gyre circulations. J. Phys. Oceanogr., 45(5), 1258-1284. doi: 10.1175/jpo-d-14-0100.1 
(a) Wind Stress

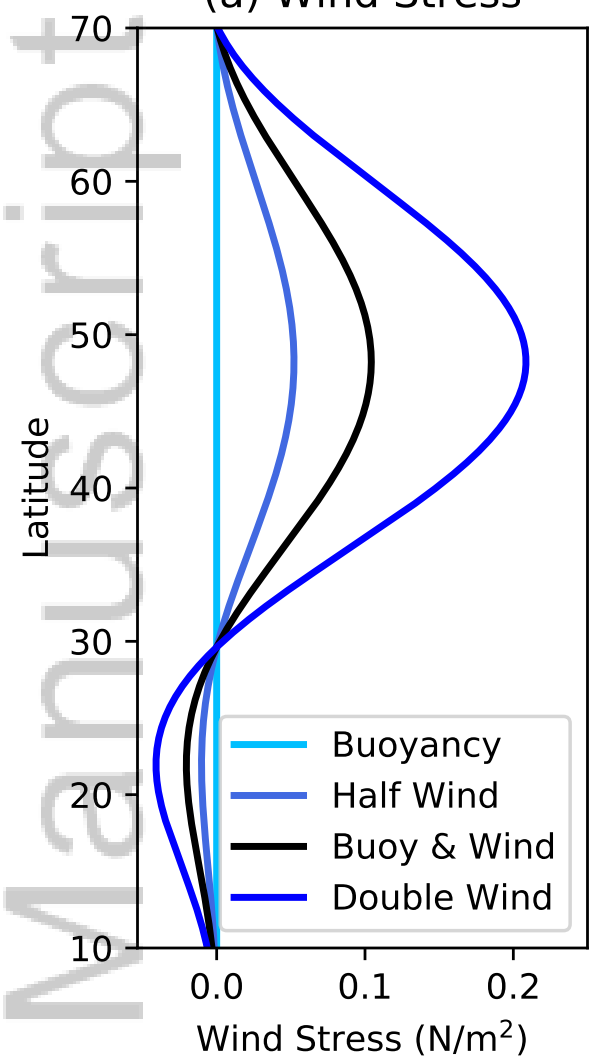

(b) Restoring Temp

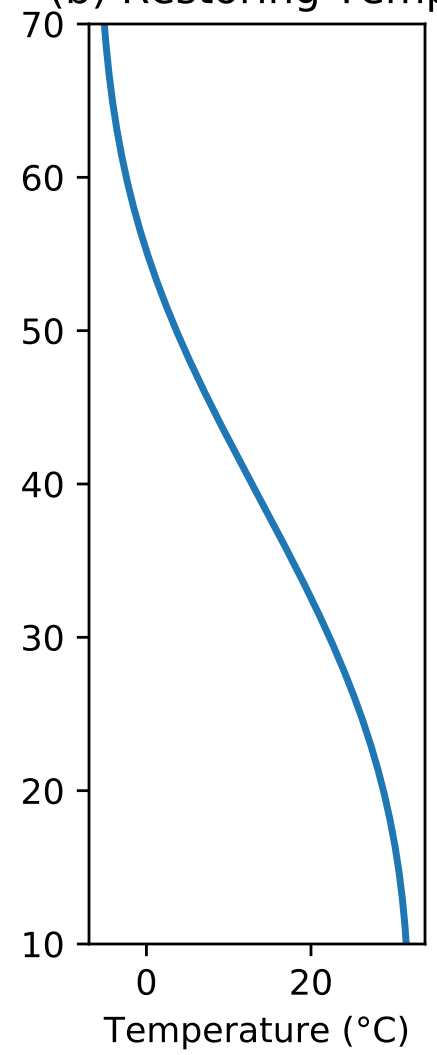

(c) Mean SSH

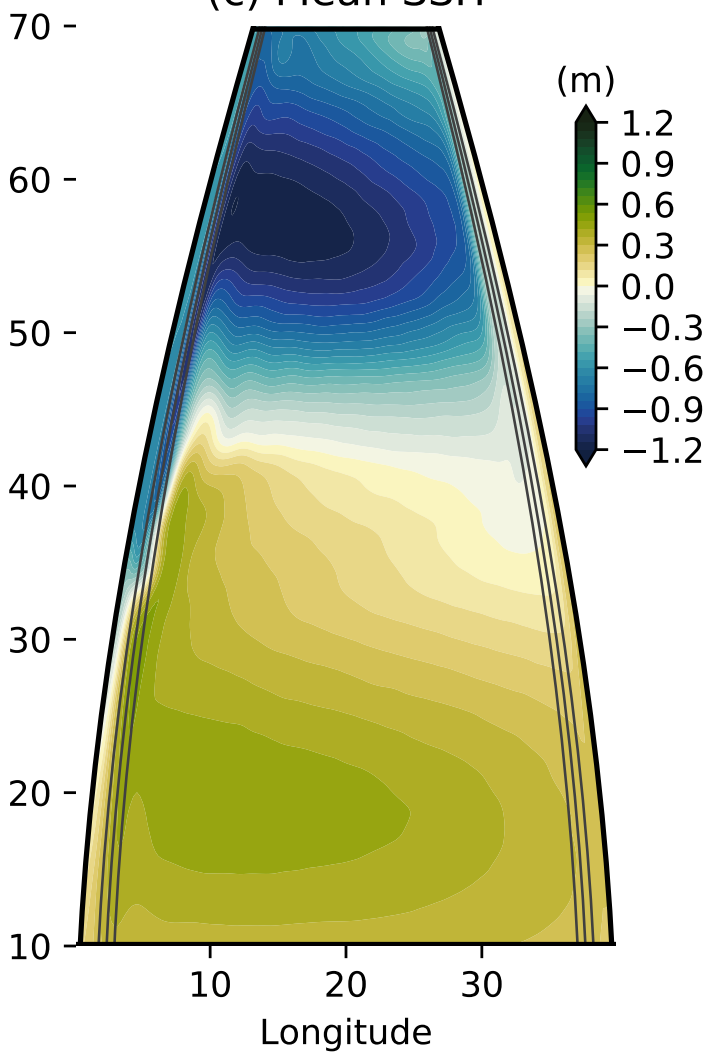

(d) Mean Heat Flux

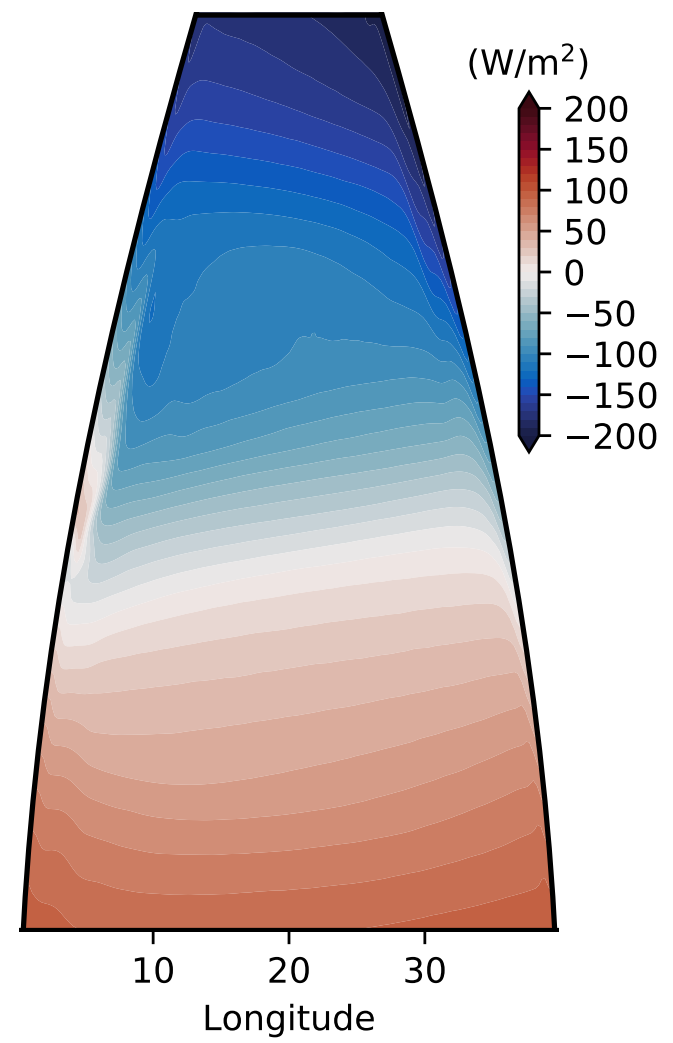

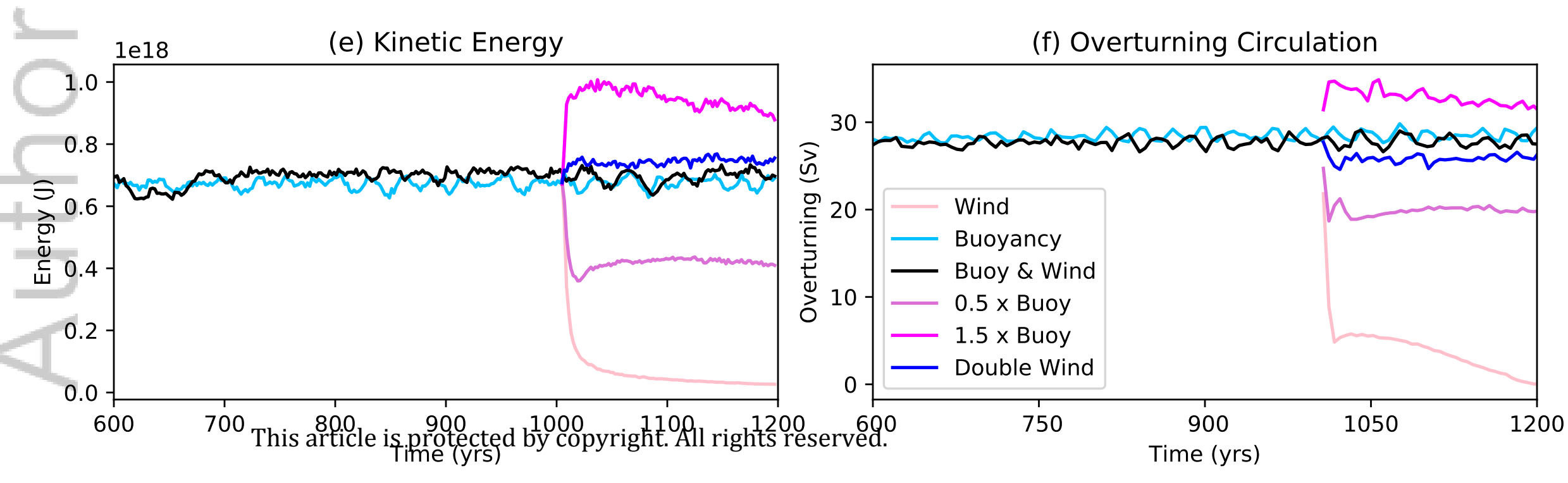


Figure 2.
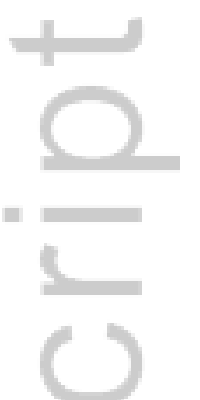

$\infty$
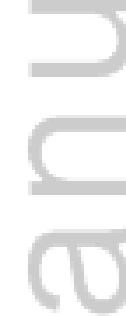

This article is protected by copyright. All rights reserved. 


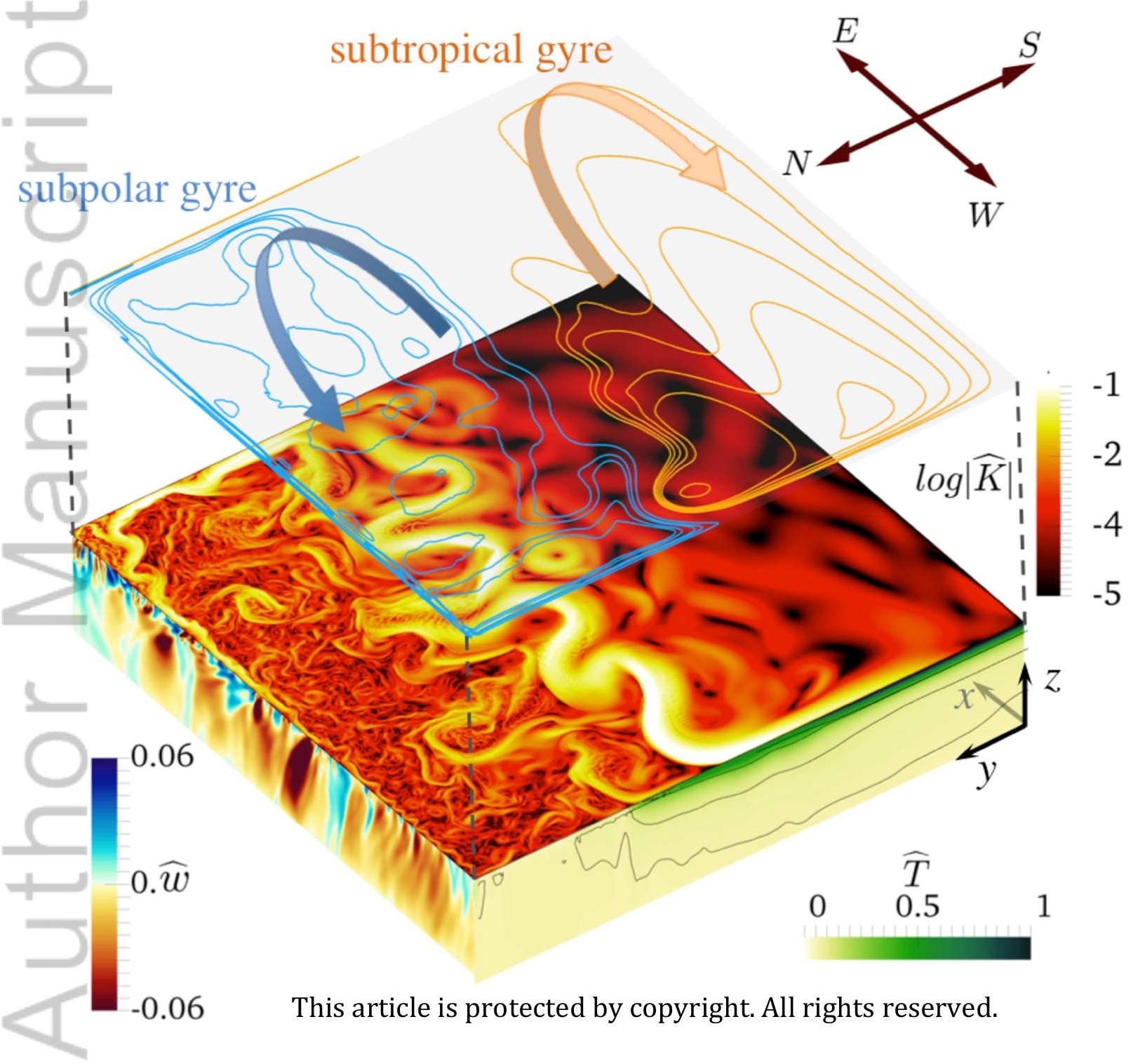




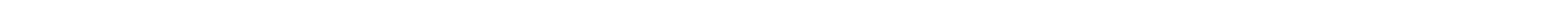


(a) Barotropic Subpolar Circulation

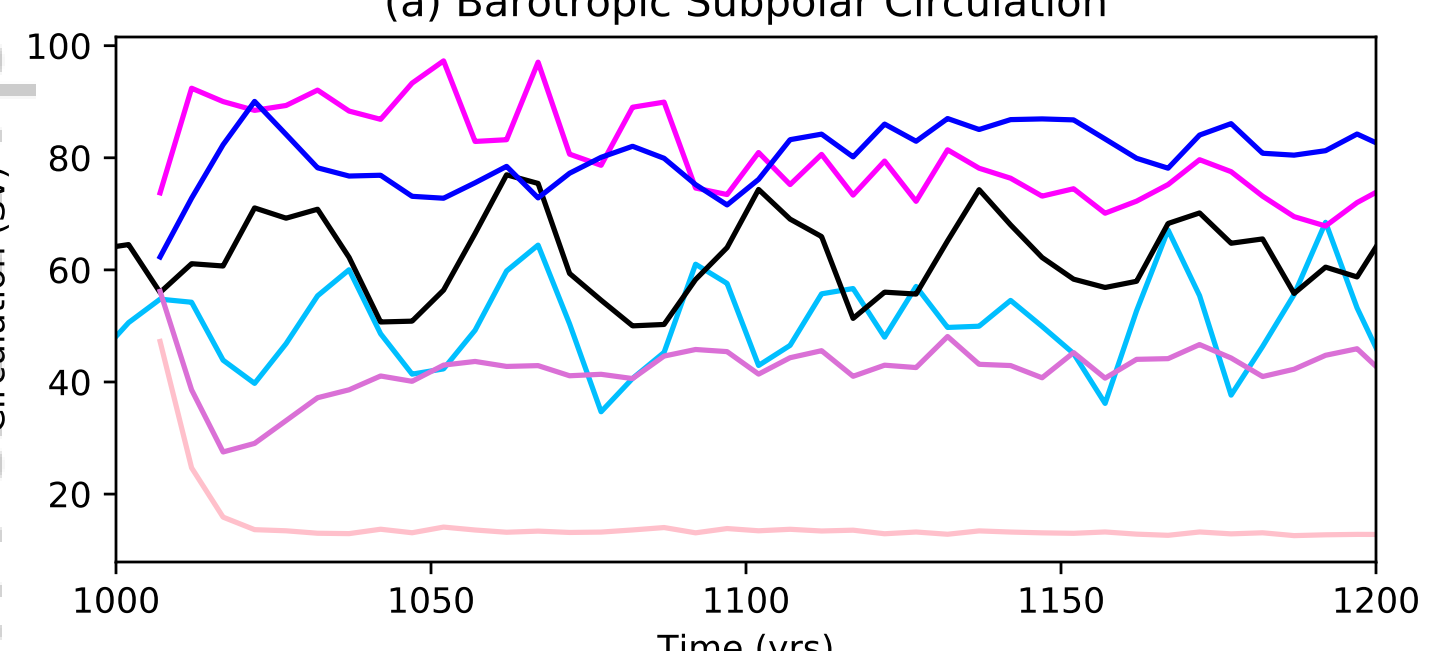

(c) Subpolar Gyre

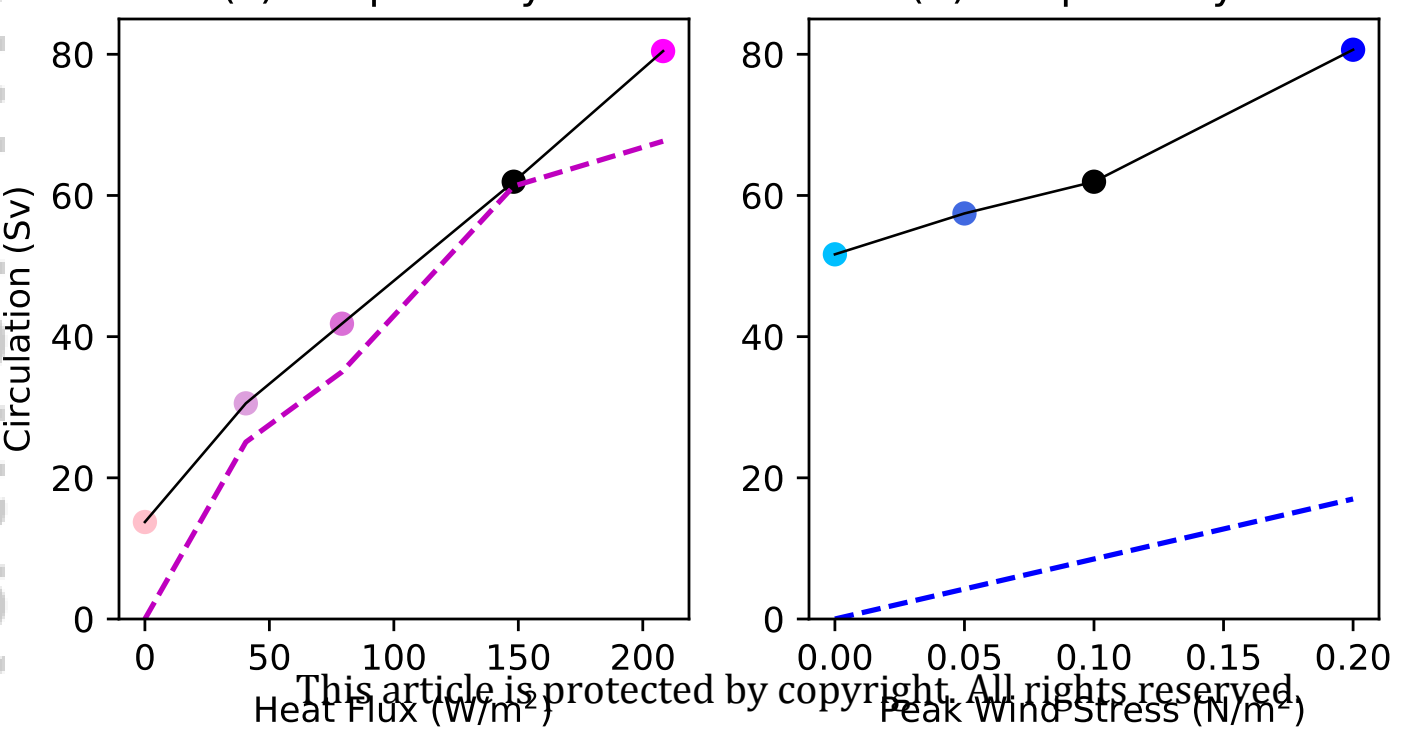

(b) Upper Ocean Subtropical Gyre

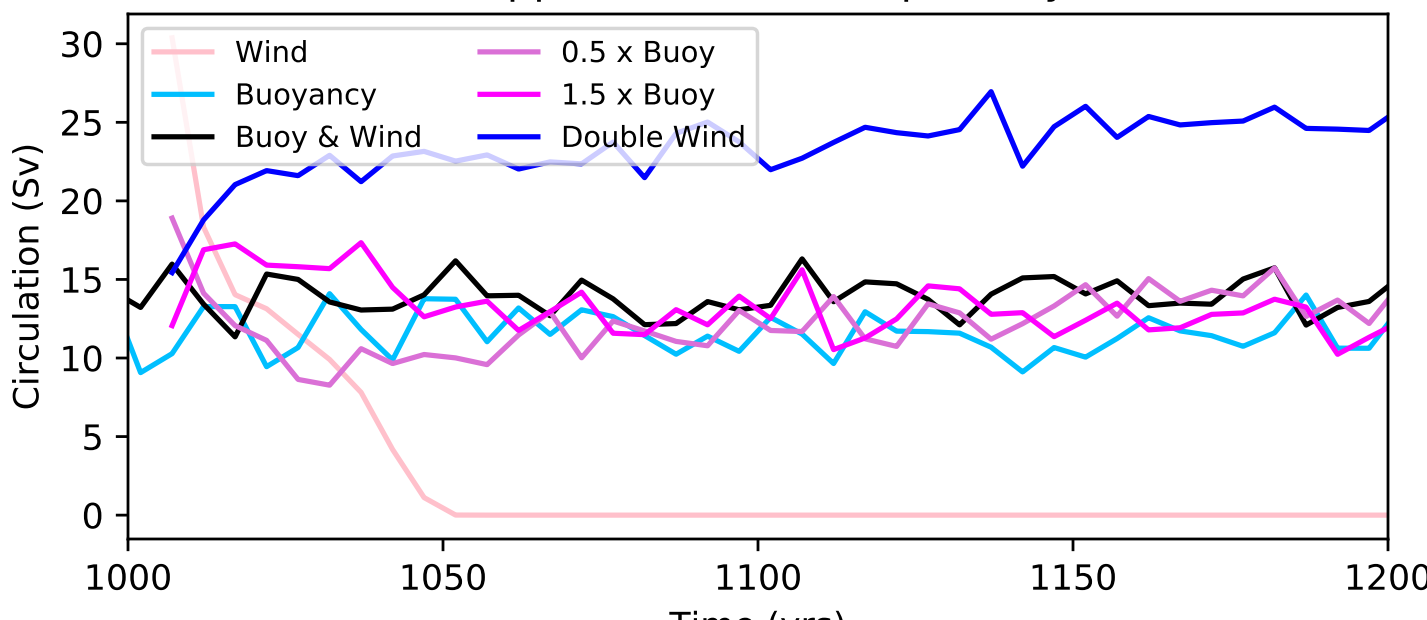

(e) Subtropical Gyre
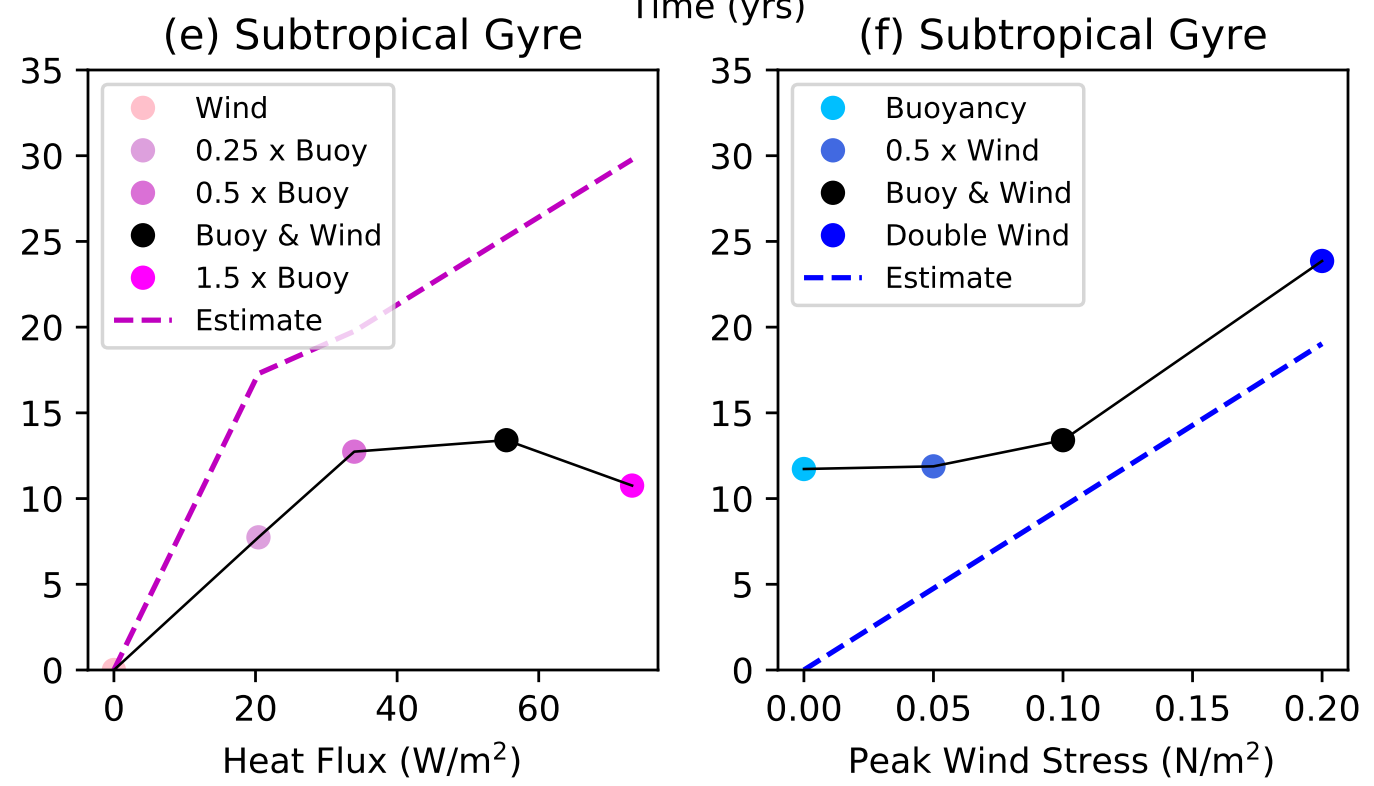
(a) Wind Stress

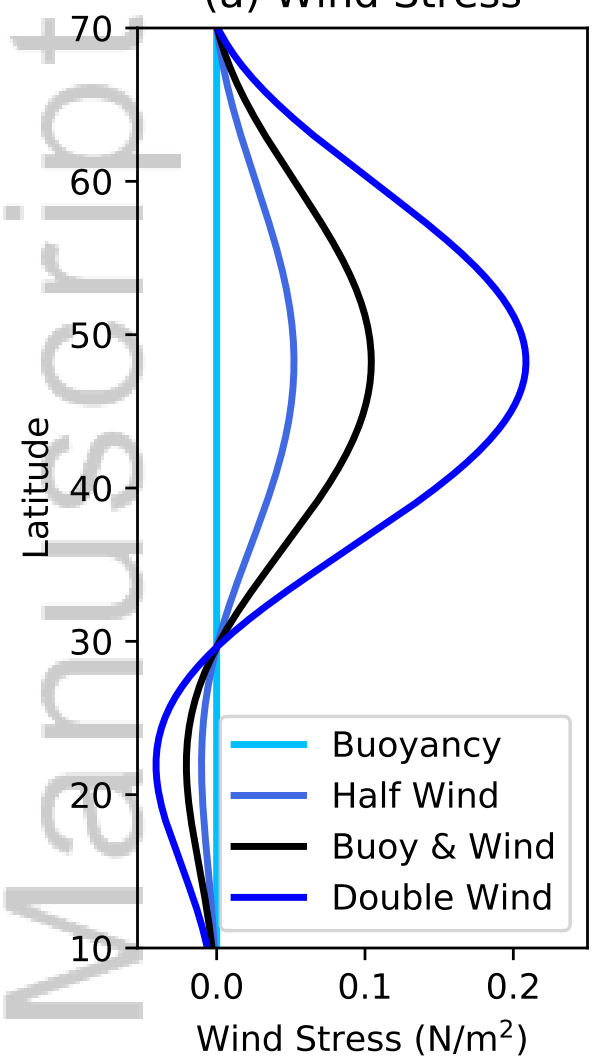

(b) Restoring Temp

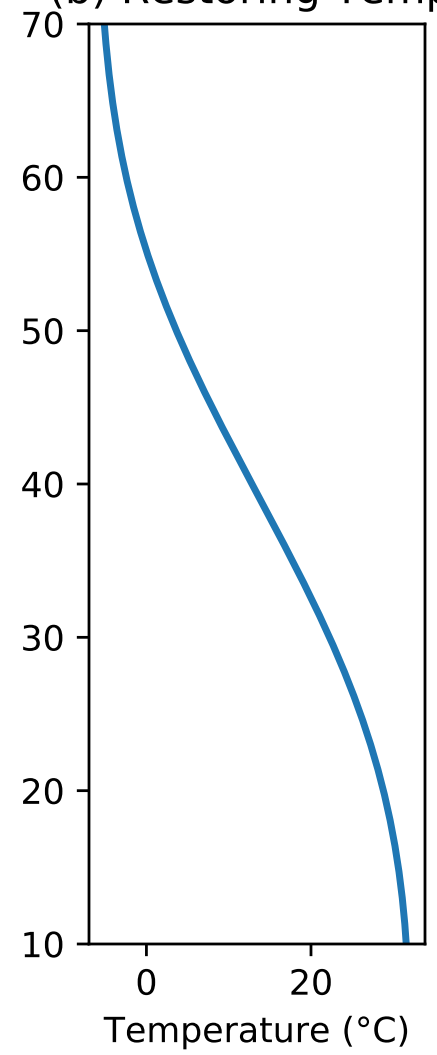

(c) Mean SSH

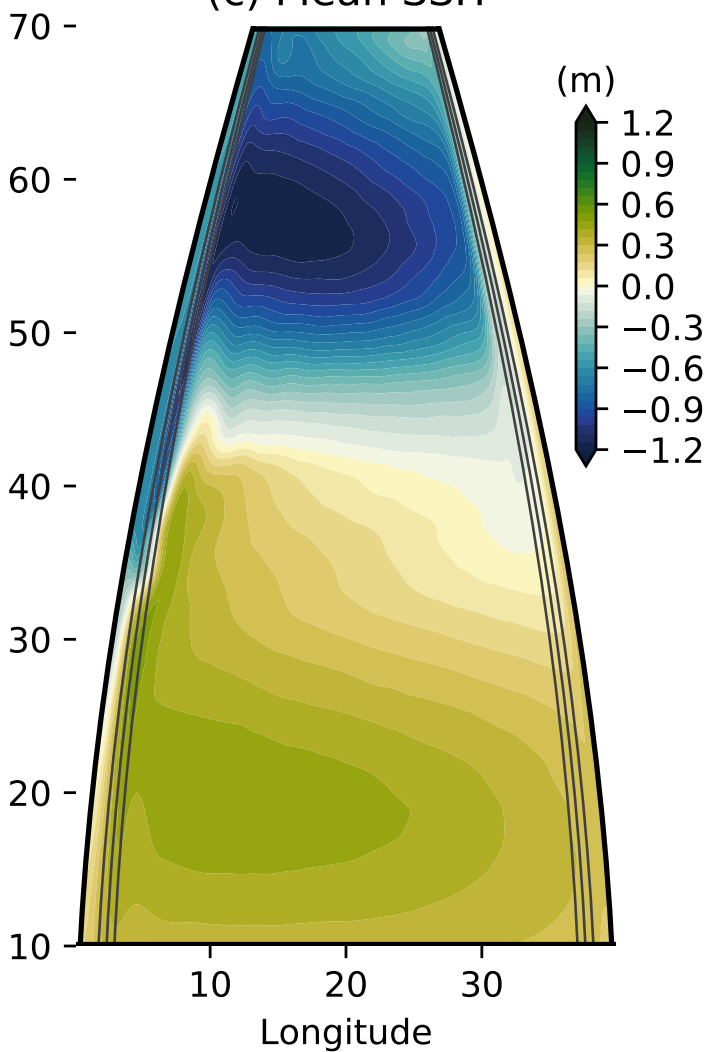

(d) Mean Heat Flux

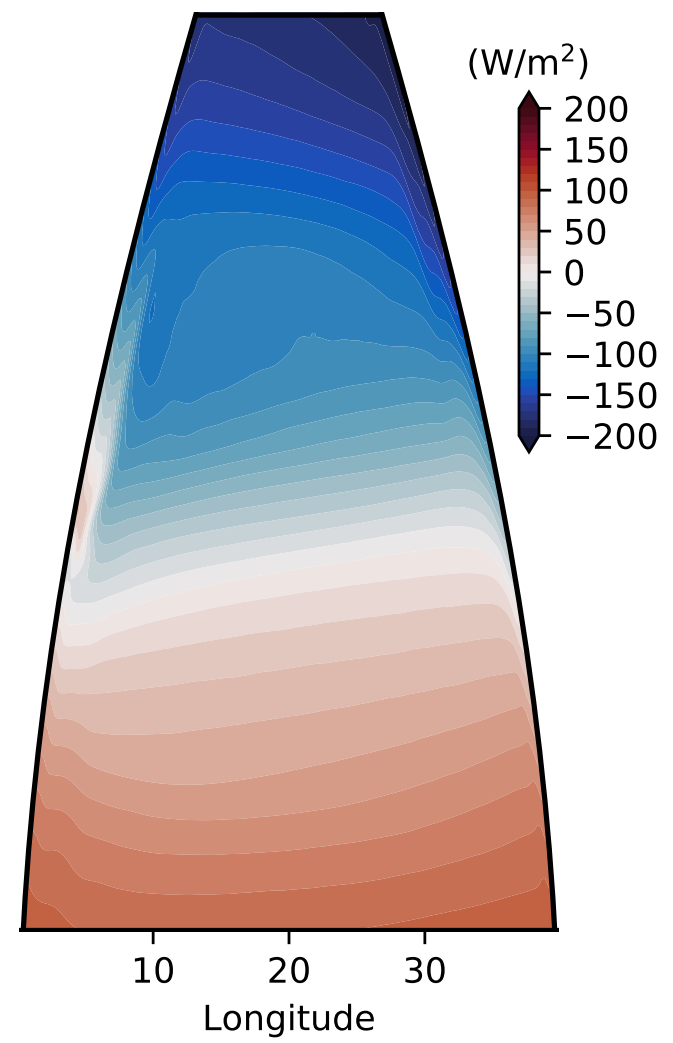

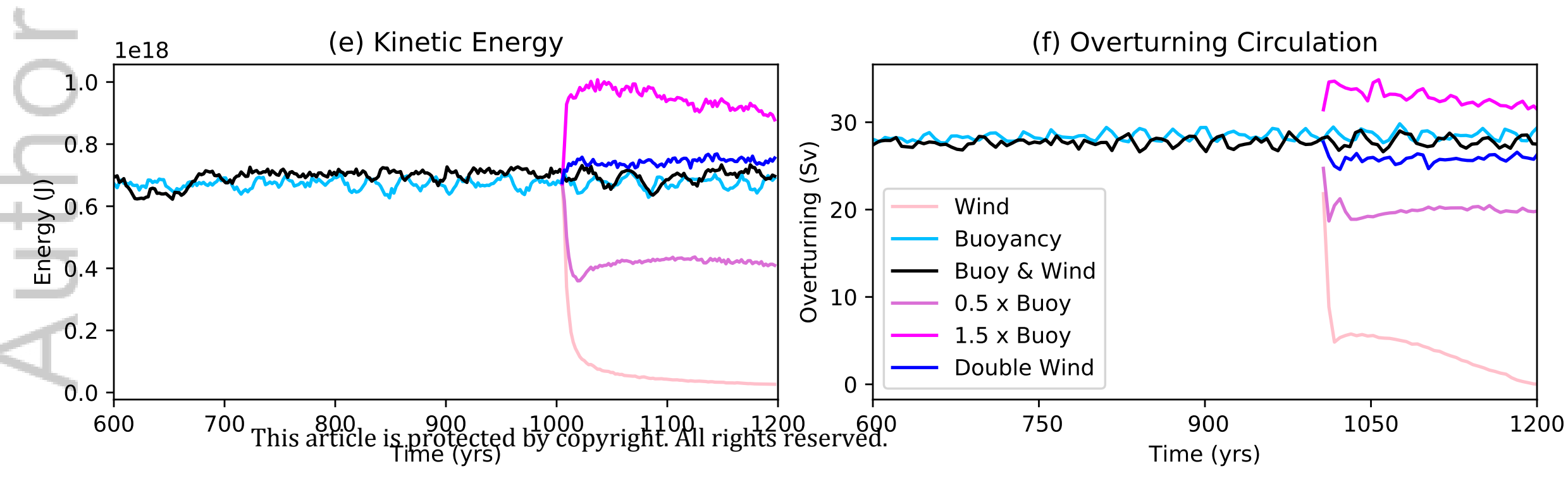



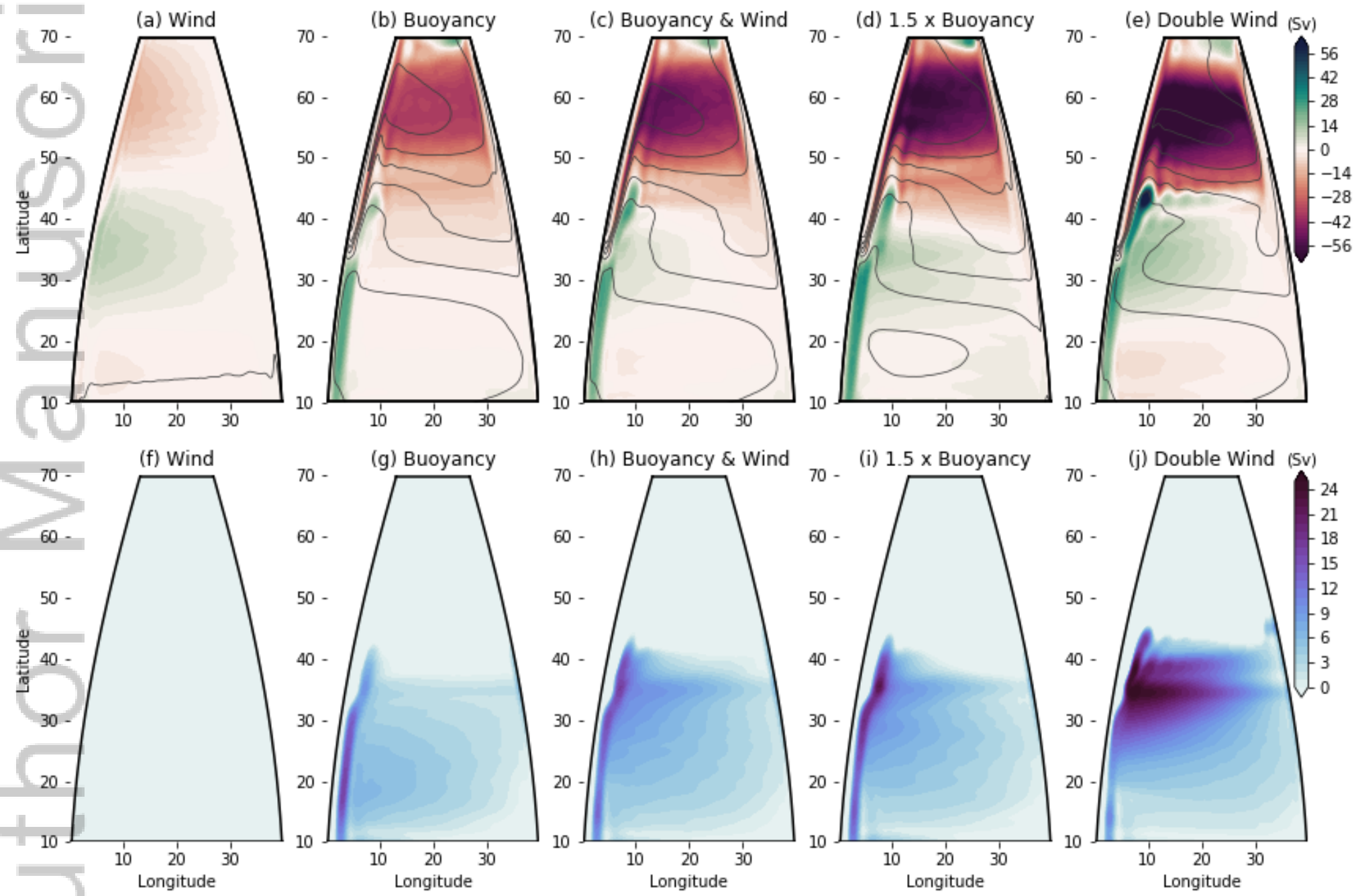

GRL_61021_2020GL088539-f03-z-.png 
(a) Barotropic Subpolar Circulation

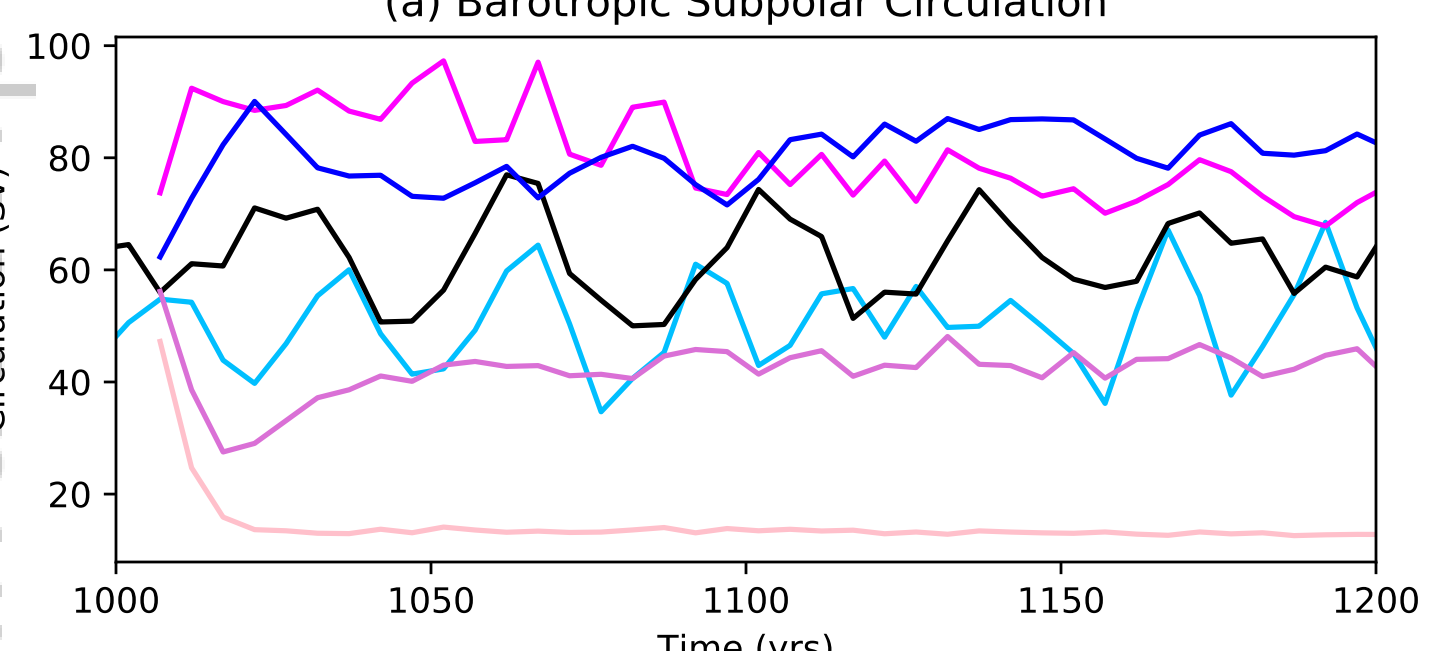

(c) Subpolar Gyre

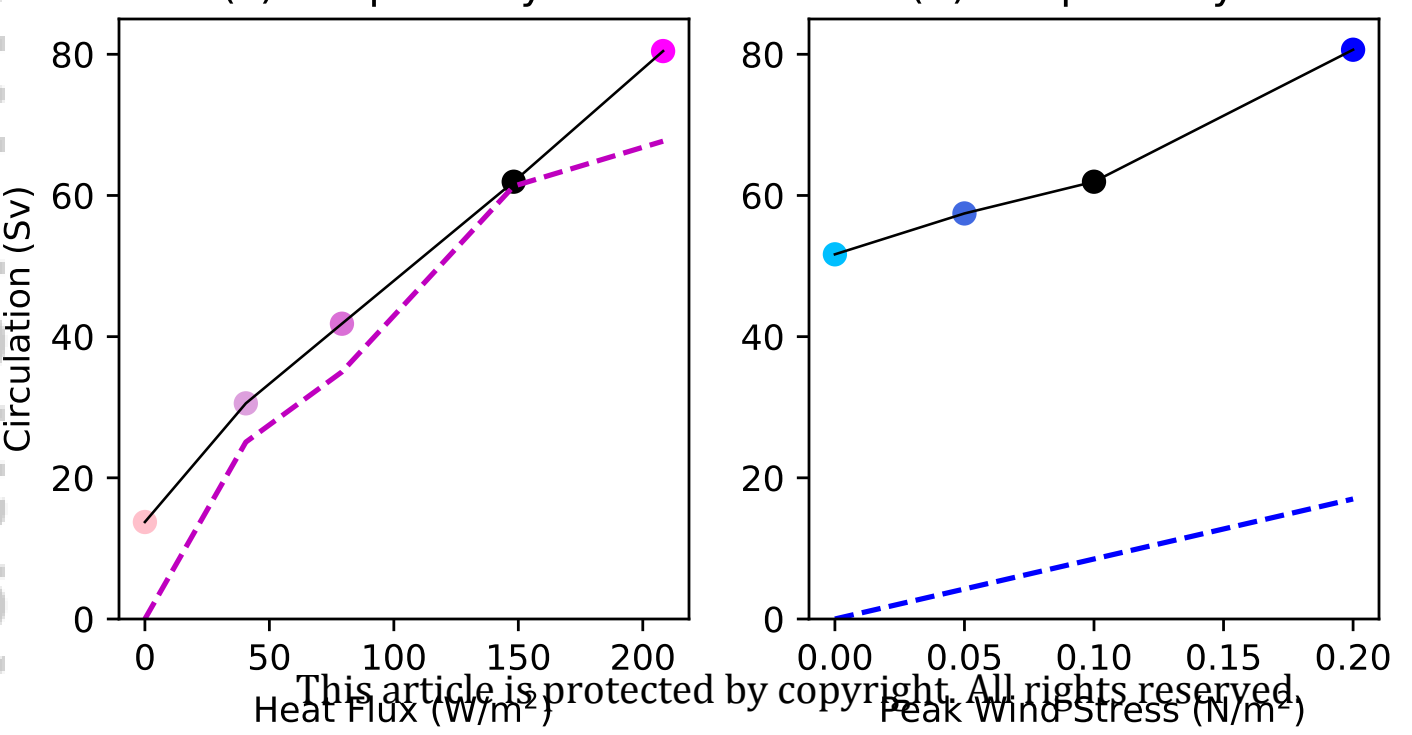

(b) Upper Ocean Subtropical Gyre

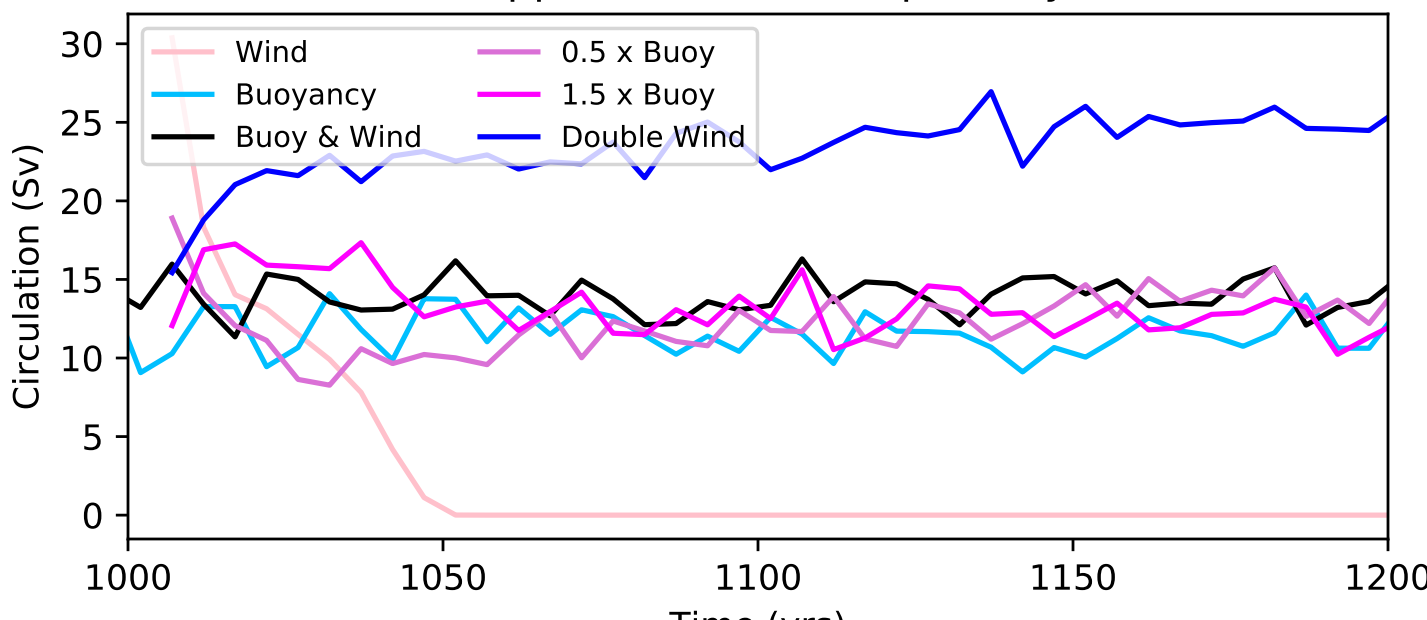

(e) Subtropical Gyre
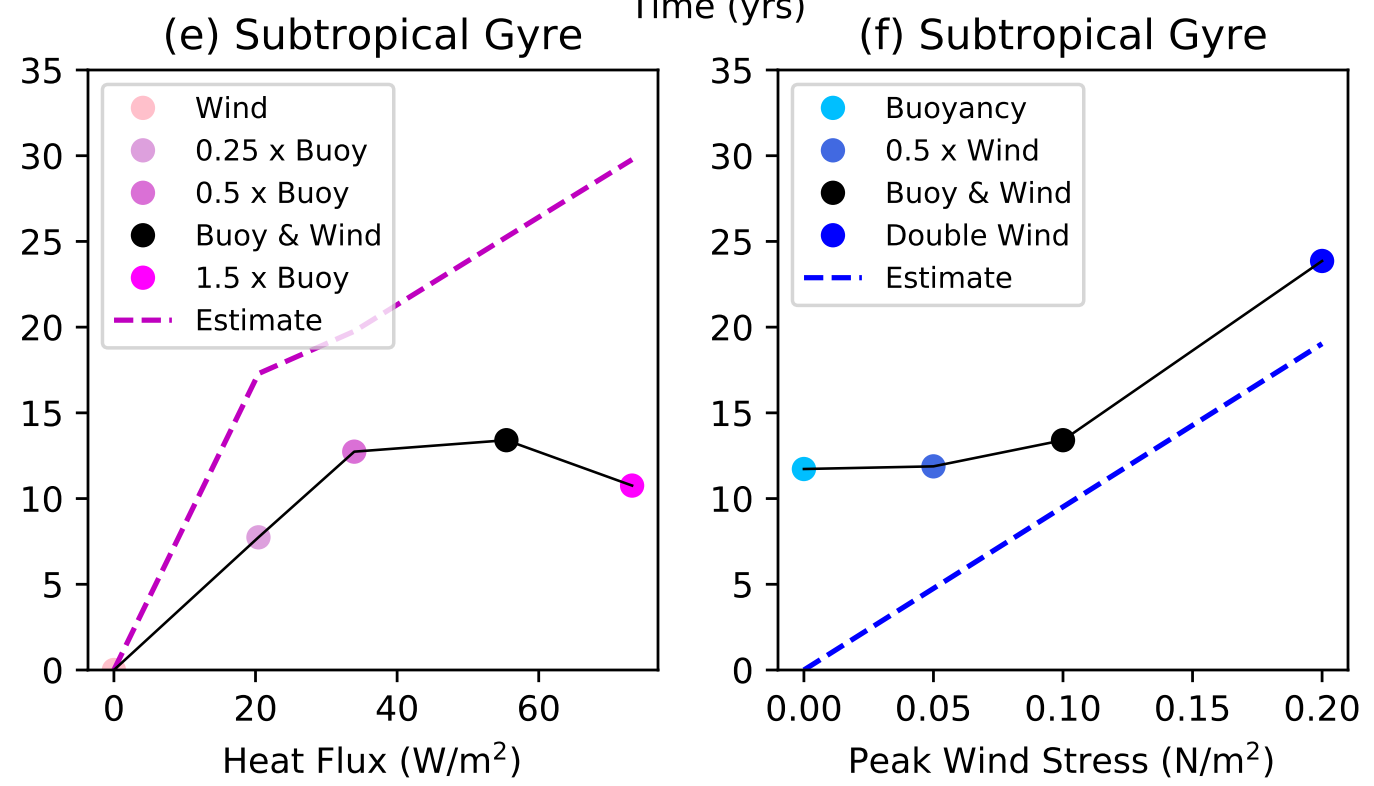


\section{University Library}

\section{- M M I E E R VA A gateway to Melbourne's research publications}

Minerva Access is the Institutional Repository of The University of Melbourne

Author/s:

Hogg, AM;Gayen, B

Title:

Ocean Gyres Driven by Surface Buoyancy Forcing

Date:

2020-08-28

Citation:

Hogg, A. M. \& Gayen, B. (2020). Ocean Gyres Driven by Surface Buoyancy Forcing.

Geophysical Research Letters, 47 (16), https://doi.org/10.1029/2020gl088539.

Persistent Link:

http://hdl.handle.net/11343/276138 